\title{
Origin and establishment of the introduced Cuban Blue Anole, Anolis allisoni, in Florida
}

\author{
Dolores G. Morris' ${ }^{1}$ Kathleen Morris ${ }^{2}$, Christopher J. Thawley ${ }^{3 *} \mathbb{D}$, Jason J. Kolbe ${ }^{3}$, and Sozos N. \\ Michaelides $^{3,4 *}$
}

'Department of Philosophy, University of South Florida, Tampa, FL 33620, USA.

${ }^{2}$ Tampa, Florida, USA.

${ }^{3}$ Department of Biological Sciences, University of Rhode Island, Kingston, RI 02881, USA.

${ }^{4}$ Department of Biology, Concordia University, Montreal H4B 1R6, QC, Canada

*Corresponding author (cthawley@gmail.com, msozos@gmail.com)

Edited by: R. Graham Reynolds. Date of publication: 21 September 2021.

Citation: Morris DG, Morris K, Thawley CJ, Kolbe JJ, Michaelides SN (2021) Origin and establishment of the introduced Cuban Blue Anole, Anolis allisoni, in Florida. Caribbean Herpetology, 78, 1-7.

DOI: https://doi.org/10.31611/ch.78

\begin{abstract}
In the state of Florida, USA, lizards of the genus Anolis are well represented with at least nine established non-native species and a single native species, $A$. carolinensis. The most recently introduced species is $A$. allisoni, a close relative to both the native $A$. carolinensis and one of the introduced species (A. porcatus). Anolis allisoni is thought to have been present in two locations in Florida since at least 2013 based on photographic evidence. Here, we analyzed mitochondrial DNA (mtDNA) sequences from these three closely related Anolis species to infer the most likely region of origin in the native range and confirm the establishment of the recent invader in Tampa, Florida. We found a single haplotype belonging to $A$. allisoni, which was closely related to native sequences from east-central Cuba. The most likely geographic origin is a tourist destination in the province of Sancti Spiritus, suggesting the potential for human-mediated introduction of $A$. allisoni to Florida. Given the evidence of hybridization within the carolinensis subgroup, the presence and establishment of the phylogenetically related and ecomorphologically similar A. allisoni may create novel opportunities for interspecific genetic exchange.
\end{abstract}

Keywords: Anolis lizards, Florida, invasions, mtDNA, Cuba

\section{Introduction}

The state of Florida in the southeastern USA is a center for non-native species introductions of reptiles and amphibians (Krysko et al. 2011). Among lizards, the genus Anolis is the most represented with nine established species in addition to the sole native species, A. carolinensis, which is found throughout Florida and the southeastern USA (Kolbe et al. 2007; Krysko et al. 2011). When introduced, closely related taxa with similar habitat use and ecology to the native species have the potential to interact strongly with and even drive evolutionary change in affected native species. For example, the invasion of the Cuban brown anole (A. sagrei) in Florida has forced A. carolinensis to move to higher perches, leading to the evolution of larger toepads in just 20 generations (Stuart et al. 2014). In another example, the introduction of the Cuban green anole, $A$. porcatus, has led to hybridization with the native species followed by genetic distinctiveness of the hybrid population in South Miami (Wegener et al. 2019). In the latter case, both species (A. carolinensis and A. porcatus) are members of the carolinensis subgroup, which includes nine species of canopy-dwelling anoles with similar coloration and morphology (Glor et al. 2005). Despite considerable divergence time between these two species, reproductive isolation between $A$. carolinensis and $A$. porcatus appears to be weak.

The latest introduction of an Anolis species in the continental USA is A. allisoni (Krysko et al. 2015). The Cuban Blue Anole, native to Cuba and islands off the coast of Honduras, Belize, and Mexico (Schwartz et al. 1991), is another member of the carolinensis subgroup. In Florida, the species is known from two locations (Fig. 1a). In 2013, 
(a)

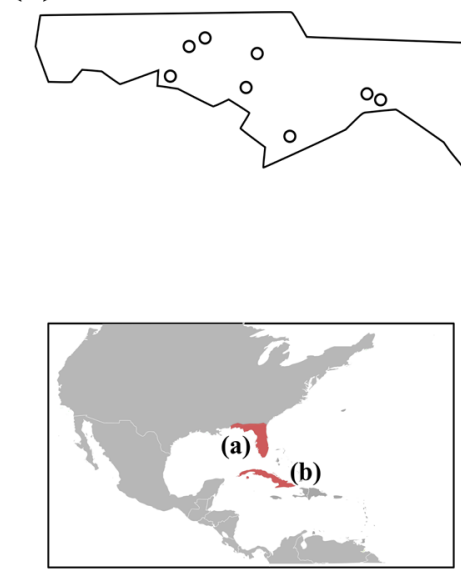

(d)

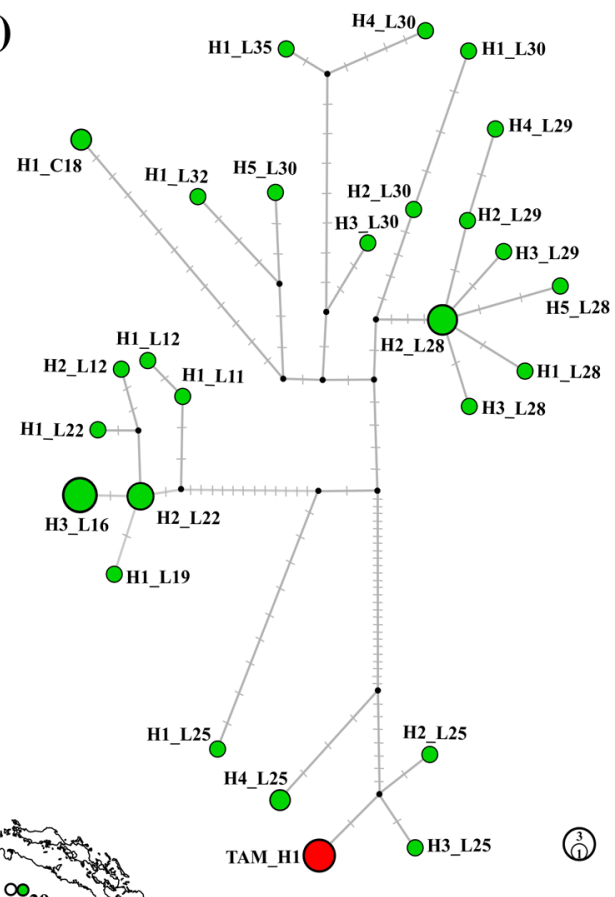

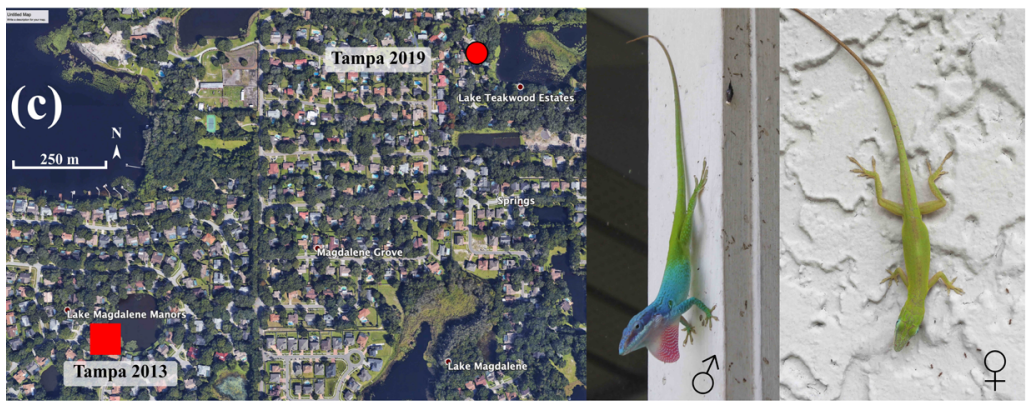
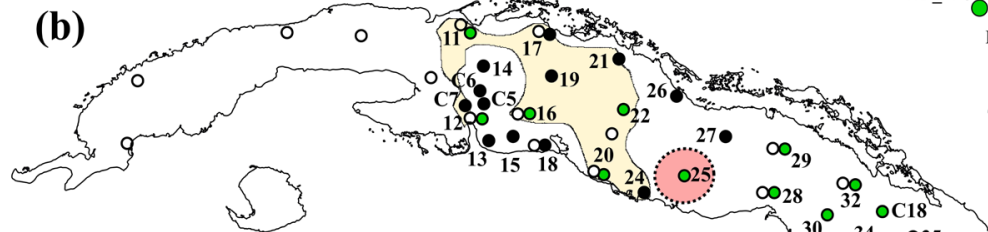

(b)

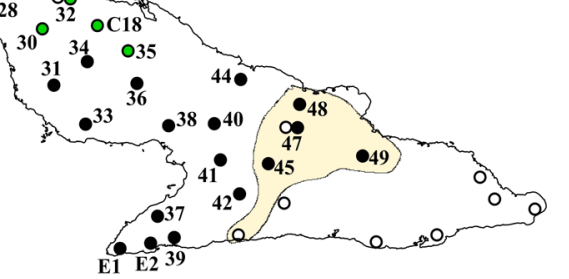

Figure 1. Sampling locations and mtDNA haplotype network. The inset map of North America shows Florida (a) and Cuba (b) shaded in red. (a) Map of Florida showing the two known introduced populations of A. allisoni in Tampa (TAM) and Naples (NAP) in red circles. Open circles represent sampling locations of mtDNA sequences for $A$. carolinensis, and the yellow square in South Miami (MIA) denotes a hybrid population derived from introduced WC A. porcatus and native A. carolinensis. (b) Map of Cuba showing sampling locations (filled circles) for native $A$. allisoni. Green circles represent locations of $A$. allisoni sequences used in the network analysis. The dotted pink-shaded area around location 25 indicates the likely geographic origin in Cuba of the A. allisoni introduced to Tampa. Open circles represent sampling locations of mtDNA sequences of $A$. porcatus, and the two yellow-shaded regions denote parts in eastern and western Cuba where introgression between $A$. porcatus and A. allisoni was previously detected. Location numbers follow Glor et al. (2005) and Cadiz et al. (2018). (c) Close-up aerial image of a portion of Tampa showing the location of the first description of A. allisoni in 2013 (red square) and the new location in 2019 (red circle) along with photos of a male and female A. allisoni (photos taken by Dolores Morris). (d) Median-joining network of 37 A. allisoni sequences belonging to the east-central subclade. The size of each circle corresponds to the number of individuals sharing that haplotype. Dashes denote mutation steps. The sequences from A. allisoni collected in Tampa are identical (TAM-H1, red circle) and most closely related to haplotypes from location 25 in Cuba.

a photographic voucher of a single male A. allisoni (UF-Herpetology 170513) was obtained in Tampa (TAM), Florida (Krysko et al. 2015). Mature male A. allisoni are readily distinguished by the distinctive blue coloration of the front half of their bodies, and A. allisoni may also be distinguished from A. carolinensis by the teardrop-like shape of their ear opening. However, subsequent surveys in Tampa by Krysko et al. (2015) failed to find other individuals of 
A. allisoni. Mitochondrial DNA (mtDNA) analyses of juvenile green anoles in the area, which are difficult to assign to species using morphology, were ascribed to A. carolinensis (Krysko et al. 2015). As such, it has been unclear whether an established population of $A$. allisoni has persisted in the area. A separate reproducing population, which has been present since at least 2014, is restricted to an outdoor courtyard in Naples (NAP; Fig. 1c), Florida (Donini et al. 2017). Nevertheless, neither of these previous studies characterized the details of the introduction(s) of A. allisoni in Florida. For instance, we do not know the geographic source(s) of introductions, likely introduction pathway, and whether sightings were due to single or multiple introductions. Genetic tools are particularly useful to address these questions which are important for management, but also for the detection and characterization of hybridization between native and introduced species (Fitzpatrick et al. 2012). In this study, we verified ongoing presence and used a mtDNA marker to confirm the phylogenetic identity and infer the most likely native-range source location(s) of $A$. allisoni in Tampa.

\section{Materials and Methods}

Sampling and genetic analyses. We caught three male lizards with $A$. allisoni phenotype from the Lake Teakwood Estates neighborhood in Tampa in 2019 (Fig. 1C). This population is $\approx 1 \mathrm{~km}$ from the sighting reported in Krysko et al. (2015). We extracted DNA from tail tips stored in $95 \%$ ethanol using the Isolate II Genomic DNA Kit (Bioline, USA) with overnight lysis. We sequenced approximately 800 base pairs (bp) of the mtDNA ND2 gene with the forward primer H5730 (5'- AGCGAATRGAAGCCCGCTGG-3', Glor et al. 2004) and the reverse L4437a (5'- AAGCTTTCGGGCCCATACC-3', Macey et al. 1997). Amplifications were carried out in a total volume of $30 \mu \mathrm{l}$ consisting of $15 \mu \mathrm{l}$ of

Table 1. Mean pairwise mtDNA (ND2 gene) divergence (Tamura-Nei, \%) between native $A$. carolinensis and each introduced Anolis species in Florida with available genetic data. Ecomorph category is from Losos (2009). Introduced A. porcatus originated from western Cuban (WC) populations and A. allisoni from east-central Cuban (ECC) populations.

\begin{tabular}{|c|c|c|}
\hline Species & Ecomorph & mtDNA divergence (\%) \\
\hline WC A. porcatus & Trunk-crown & 9.6 \\
\hline ECC A. allisoni & Trunk-crown & 16.2 \\
\hline A. equestris & Crown-giant & 28.8 \\
\hline A. chlorocyanus & Trunk-crown & 30.0 \\
\hline A. cristatellus & Trunk-ground & 30.9 \\
\hline A. garmani & Crown-giant & 31.0 \\
\hline A. sagrei & Trunk-ground & 33.4 \\
\hline A. cybotes & Trunk-ground & 34.5 \\
\hline A. distichus & Trunk & 35.3 \\
\hline
\end{tabular}

MyTaq HS Mix (Bioline), $1.2 \mu \mathrm{l}\left(0.4 \mathrm{mM}\right.$ ) of each primer, $10.6 \mu \mathrm{l}$ PCR grade $\mathrm{H}_{2} \mathrm{O}$ and $2 \mu$ l template DNA (20 ng). PCR conditions were as follows: an initial denaturation step at $95^{\circ} \mathrm{C}$ for $1 \mathrm{~min}$, followed by 30 cycles at $95^{\circ} \mathrm{C}$ for $1 \mathrm{~min}$, $53^{\circ} \mathrm{C}$ for $35 \mathrm{sec}$ and $72^{\circ} \mathrm{C}$ for $80 \mathrm{sec}$, and a final extension step at $72^{\circ} \mathrm{C}$ for $5 \mathrm{~min}$. PCR products were purified using the Isolate II PCR Kit (Bioline), and sequencing reactions were performed on the ABI 3130xI genetic analyzer at the University of Rhode Island (URI) Genomics and Sequencing Center.

Mitochondrial DNA sequences from both directions were corrected by eye and aligned to obtain a consensus sequence. All sequences were then aligned using MAFFT (Katoh et al. 2002) implemented in Geneious 8 (Kearse et al. 2012) and trimmed to a uniform length of 798 bp. A unique sequence was submitted to GenBank under the accession number MZ475900.

Phylogenetic analyses. We used phylogenetic analyses to reconstruct relationships among haplotypes and to determine the genetic origin of the introduced haplotypes. We combined our sequences with 348 sequences (of varying lengths) obtained from GenBank representing native range A. allisoni from Cuba (Glor et al. 2004; Cádiz et al. 2018), A. porcatus from Cuba (Glor et al. 2004), A. allisoni x A. porcatus hybrids from Cuba (Glor et al. 2004), 
Table 2. Mean pairwise mtDNA (ND2 gene) divergence between pairs of Anolis species with genetic evidence of hybridization and introgression. The abbreviations denote sequences sampled from western (WC) and eastern (EC) Cuban populations.

\begin{tabular}{lcc}
\hline \multicolumn{1}{c}{ Species pair } & mtDNA divergence (\%) & Study \\
\hline A. carolinensis x WC A. porcatus & 9.6 & Wegener et al. 2019 \\
EC A. allisoni x EC A. porcatus & 10.0 & Glor et al. 2004; 2005 \\
WC A. sagrei x A. quadriocellifer & 10.2 & Kolbe et al. 2004; \\
& & (Reynolds et al. 2020) \\
WC A. allisoni x WC A. porcatus & 14.3 & Glor et al. 2004; 2005 \\
A. krugi x A. pulchellus & 15.4 & Jezkova et al. 2013 \\
\hline
\end{tabular}

native A. carolinensis from Florida (Kolbe et al. 2007; Tollis et al. 2012; Campbell-Staton et al. 2012), A. carolinensis $x$ A. porcatus hybrids from South Miami, FL (Wegener et al. 2019), and sequences of green anoles previously sampled from Tampa, FL and ascribed to A. carolinensis (Krysko et al. 2015). We also obtained from GenBank three sequences belonging to the Cuban species A. oporinus, A. isolepis and A. altitudinalis (Glor et al. 2004) to use as outgroups.

We constructed the phylogenetic tree using a Bayesian inference $(\mathrm{BI})$ with the add-on plugin of MrBayes (Huelsenbeck et al. 2001), implemented in Geneious 8 (Kearse et al. 2012). The GTR + G + I substitution model was selected based on the lowest BIC criterion in MEGA X (Stecher et al. 2020), and the Bl analysis was run with four chains of 2,000,000 generations sampling every 500 trees. We discarded (burn-in-length) the first $10 \%$ of trees after checking for convergence of the chains (trace viewer within Geneious 8), and posterior probability branch support was estimated from the $50 \%$ majority-rule consensus tree. To assess and visualize better the phylogenetic relationships among haplotypes, we also constructed a median-joining network in NETWORK v10 (Bandelt et al. 1999) using a subset of sequences $(n=37)$ belonging to the east-central $A$. allisoni subclade (see Results). This method uses median vectors as a hypothetical ancestral sequence required to connect existing sequences within the network with maximum parsimony. For this analysis, all sequences were trimmed to $798 \mathrm{bp}$ to match the newly-generated sequence lengths.

In addition, we gathered unique sequences (introduced haplotypes of the ND2 gene only) from established non-native anoles in Florida from GenBank (Kolbe et al. 2007) and calculated mean pairwise mtDNA divergence between these and the native haplotypes of $A$. carolinensis using MEGA X (Stecher et al. 2020). Combined with ecomorphological categorization (i.e., habitat specialist group, Losos 2009), we discuss how human-mediated introductions may create opportunities for hybridization between the native (A. carolinensis) and the introduced Anolis species as well as among introduced Anolis species in Florida.

\section{Results and Discussion}

Genetic samples from all three presumptive A. allisoni individuals sampled from Tampa were nested in the A. allisoni clade, providing conclusive evidence that they are indeed $A$. allisoni or hybrids with A. allisoni maternal mtDNA. More than 50 adult $A$. allisoni of both sexes were observed in our focal area (DM and KM personal observation) covering several residences and landscaped vegetation over an area of approximately $0.02 \mathrm{~km}^{2}$. We observed individuals conducting dewlap displays, engaging in combat, and mating, supporting their establishment success. Anecdotal interviews with local residents and photographic evidence indicate that $A$. allisoni has been in the area since at least 2017. It seems likely that the previous sighting in this area $(\approx 1 \mathrm{~km}$ distance, Krysko et al. 2015) is from the same population. This population has also survived through multiple winters (DM and KM personal observation, spring 2021), suggesting that cold temperatures and potential associated mortality have not impacted its establishment.

All three individuals sampled in Tampa shared the same haplotype (TAM-H1). The overall topology of our phylogenetic tree (not shown) is similar to the one described by Glor et al. (2004) supporting two subclades for A. allisoni (western and east-central), which are sister to A. porcatus from eastern Cuba. The haplotype sampled in 
this study clusters within the east-central A. allisoni subclade, and the median-joining network (Fig. 1d) shows that the TAM-H1 haplotype is genetically similar (three nucleotides different) to haplotypes from the province of Sancti Spiritus in Cuba (location 25 in Fig. 1 b as described in Glor et al. 2004).

Our finding is the first verification of the genetic Cuban origin of $A$. allisoni in Florida. The fact that this species was observed in 2013 (Krysko et al. 2015) and that we recently collected it, provides evidence that the species is reproducing, established, and likely dispersing across the urban landscape of Tampa. The province of Sancti Spiritus, the likely geographic origin in east-central Cuba, has many attractions for tourists (e.g., UNESCO World Heritage sites), suggesting a human-mediated introduction. Whether the introduction was deliberate, such as via the pet-trade, or accidental, is unknown. The species has also been introduced to Quintana Roo, Mexico as well as the island of Utila and city of La Ceiba, both in Honduras (McCranie et al. 2015). In the latter case, both locations (Utila and La Ceiba) are connected via ferry to the island of Roatan, where A. allisoni is native (McCranie et al. 2015), suggesting a nearby source for introductions.

When introduced and native species are phylogenetically related with similar habitat use and ecology, the native species may face both ecological and evolutionary pressure through competitive exclusion, niche displacement, hybridization, and introgression (Blackburn et al. 2014). Three introduced Anolis species in Florida (A. porcatus, A. allisoni and A. chlorocyanus) occupy the same structural habitat as the native $A$. carolinensis (all belong to the trunk-crown ecomorph, Table 1) and are similar in morphology and behavior (Losos 2009). Furthermore, two of these species, A. porcatus and A. allisoni, are closely related phylogenetically to the native anole with $9.6 \%$ (western Cuban haplotypes) and 16.2\% mtDNA sequence divergence, respectively (Table 1). Specifically, within the carolinensis subgroup, hybridization events suggest that species boundaries and reproductive isolation might be weak. In western and eastern parts of Cuba where A. allisoni and A. porcatus occur sympatrically and have a mean pairwise mtDNA divergence of $10.0-14.3 \%$ (Glor et al. 2005), introgression is bidirectional (Figure 1; Glor et al. 2004). In Florida, introduced western Cuban (WC) A. porcatus in South Miami hybridizes with A. carolinensis; these taxa have a mean pairwise mtDNA divergence of $9.6 \%$ (Wegener et al. 2019). In comparison, the mean pairwise mtDNA divergence between A. carolinensis and eastern Cuban (EC) A. porcatus is 15.9\% (Glor et al. 2005). Thus, given the phylogenetic and ecological similarity of $A$. allisoni to the native green anole in Florida (Table 1), the potential for hybridization exists.

Human-mediated introductions often create opportunities for intra- and inter-specific hybridization by removing spatial barriers between previously allopatric taxa (e.g. Kolbe et al. 2004; Michaelides et al. 2013; Stephens et al. 2020). For the non-native species, such opportunities may facilitate establishment, adaptation, and range expansion through increased diversity, hybrid vigor, and the generation of novel genotypes (Ellstrand et al. 2000; Rius et al. 2014). For the native species, however, interspecific hybridization with a non-native species could lead to genetic swamping and potentially extinction of local lineages (Todesco et al. 2016; Ottenburghs 2021). However, anthropogenic hybridization can also provide opportunities for exchange of adaptive genetic variation and speciation (see review by Ottenburghs 2021). The $16.2 \%$ mtDNA sequence divergence between the recently introduced A. allisoni and the native $A$. carolinensis is only slightly more than the divergence between successfully hybridizing species in Puerto Rico (Table 2). Hybridization between native A. carolinensis and all other introduced Anolis species in Florida (besides A. porcatus) is much less likely given the greater mtDNA sequence divergence with these species, all $28.8 \%$ or more (Table 1). Among the introduced species, opportunities for hybridization might occur for A. porcatus and A. allisoni, however, both are currently established in different locations in Florida. The closest A. allisoni population to South Miami, where WC A. porcatus was introduced, is in Naples ( $200 \mathrm{~km}$ to the west). The phylogenetic identity of this population is still unknown, but if this introduction has a WC A. allisoni origin then hybridization with WC A. porcatus is very likely upon future secondary contact.

In conclusion, photographic, observational, and genetic evidence suggest that $A$. allisoni is well established in this Tampa neighborhood, having likely dispersed at least $1 \mathrm{~km}$ through suburban habitats. Knowledge of the geographic origin of this introduced species in east-central Cuba could guide future sampling (both in the 
native and introduced range) and use of bi-parentally inherited nuclear markers to investigate whether hybridization is occurring and the potential consequences thereof.

\section{Acknowledgements}

Funding for the genetic work was provided from the University of Rhode Island.

\section{Author Contributions}

DM and KM initiated the research, collected photographs and specimens, and revised the manuscript; CT coordinated the research, drafted and revised the manuscript; SM conducted the laboratory work, analyses and co-wrote the manuscript; JK provided funding, contributed to the interpretation of data and revised the manuscript. All authors approved the final version.

\section{References}

Bandelt HJ, Forster P, \& Röhl A (1999) Median-joining networks for inferring intraspecific phylogenies. Molecular Biology and Evolution 16, 37-48. Article

Blackburn TM, EssI F, Evans T, Hulme PE, Jeschke JM, Kühn I, Kumschick S, Marková Z, Mrugała A, Nentwig W, Pergl J, Pyšek P, et al. (2014) A Unified Classification of Alien Species Based on the Magnitude of their Environmental Impacts. PLoS Biology 12, e1001850. Article

Cádiz A, Nagata N, Díaz LM, Suzuki-Ohno Y, Echenique-Díaz LM, Akashi HD, Makino T, \& Kawata M (2018) Factors affecting interspecific differences in genetic divergence among populations of Anolis lizards in Cuba. Zoological Letters 4, 1-12. Article

Campbell-Staton SC, Goodman RM, Backström N, Edwards SV, Losos JB, \& Kolbe JJ (2012) Out of Florida: mtDNA reveals patterns of migration and Pleistocene range expansion of the Green Anole lizard (Anolis carolinensis). Ecology and Evolution 2, 2274-2284. Article

Donini J, \& Allman P (2017) Geographic distribution: Anolis allisoni (Allison's anole). Herpetological Review 48, 14

Ellstrand NC, \& Schierenbeck KA (2000) Hybridization as a stimulus for the evolution of invasiveness in plants? Proceedings of the National Academy of Sciences 97, 7043-7050. Article

Fitzpatrick BM, Fordyce JA, Niemiller ML, \& Reynolds RG (2012) What can DNA tell us about biological invasions? Biological Invasions 14, 245-253. Article

Glor RE, Gifford ME, Larson A, Losos JB, Schettino LR, Lara ARC, \& Jackman TR (2004) Partial island submergence and speciation in an adaptive radiation: a multilocus analysis of the Cuban green anoles. Proceedings of the Royal Society of London. Series B: Biological Sciences 271, 2257-2265. Article

Glor RE, Losos JB, \& Larson A (2005) Out of Cuba: overwater dispersal and speciation among lizards in the Anolis carolinensis subgroup. Molecular Ecology 14, 2419-2432. Article

Huelsenbeck JP, \& Ronquist F (2001) MRBAYES: Bayesian inference of phylogenetic trees. Bioinformatics (Oxford, England) $17,754-755$. Article

Katoh K, Misawa K, Kuma K, \& Miyata T (2002) MAFFT: a novel method for rapid multiple sequence alignment based on fast Fourier transform. Nucleic Acids Research 30, 3059-3066. Article

Kearse M, Moir R, Wilson A, Stones-Havas S, Cheung M, Sturrock S, Buxton S, Cooper A, Markowitz S, Duran C, Thierer T, Ashton B, et al. (2012) Geneious Basic: An integrated and extendable desktop software platform for the organization and analysis of sequence data. Bioinformatics 28, 1647-1649. Article

Kolbe JJ, Glor RE, Rodríguez Schettino L, Lara AC, Larson A, \& Losos JB (2004) Genetic variation increases during biological invasion by a Cuban lizard. Nature 431, 177-181. Article

Kolbe JJ, Glor RE, Schettino LR, Lara AC, Larson A, \& Losos JB (2007) Multiple Sources, Admixture, and Genetic Variation in Introduced Anolis Lizard Populations. Conservation Biology 21, 1612-1625. Article 
Krysko KL, Burgess JP, Rochford MR, Gillette CR, Cueva D, Enge KM, Somma LA, Stabile JL, Smith DC, Wasilewski JA, Kieckhefer lii GN, Granatosky MC, et al. (2011) Verified non-indigenous amphibians and reptiles in Florida from 1863 through 2010: Outlining the invasion process and identifying invasion pathways and stages. Zootaxa 3028, 1-64. Article

Krysko KL, MacKenzie-Krysko C, Connor LL, Alfonso YU, \& Nunez LP (2015) The Cuban Blue Anole, Anolis allisoni Barbour 1928 (Squamata: Dactyloidae), a New Nonnative Lizard Introduced in Florida. IRCF Reptiles \& Amphibians 22, 128-131. Article

Losos J (2009) Lizards in an Evolutionary Tree: Ecology and Adaptive Radiation of Anoles. University of California Press.

Macey JR, Larson A, Ananjeva NB, \& Papenfuss TJ (1997) Evolutionary Shifts in Three Major Structural Features of the Mitochondrial Genome Among Iguanian Lizards. Journal of Molecular Evolution 44, 660-674. Article

McCranie JR, \& Köhler G (2015) The Anoles (Reptilia: Squamata: Dactyloidae: Anolis: Norops) of Honduras. Systematics, Distribution, and Conservation. Bulletin of the Museum of Comparative Zoology 161, 1-280. Article

Michaelides S, While GM, Bell C, \& Uller T (2013) Human introductions create opportunities for intra-specific hybridization in an alien lizard. Biological Invasions 15, 1101-1112. Article

Ottenburghs J (2021) The genic view of hybridization in the Anthropocene. Evolutionary Applications n/a. Article

Reynolds RG, Kolbe JJ, Glor RE, López-Darias M, Gómez Pourroy CV, Harrison AS, Queiroz K, Revell LJ, \& Losos JB (2020) Phylogeographic and phenotypic outcomes of brown anole colonization across the Caribbean provide insight into the beginning stages of an adaptive radiation. Journal of Evolutionary Biology 33, 468494. Article

Rius M, \& Darling JA (2014) How important is intraspecific genetic admixture to the success of colonising populations? Trends in Ecology \& Evolution 29, 233-242. Article

Schwartz A, \& Henderson RW (1991) Amphibians and reptiles of the West Indies: descriptions, distributions, and natural history. University of Florida Press, Gainesville, Florida, USA.

Stecher G, Tamura K, \& Kumar S (2020) Molecular Evolutionary Genetics Analysis (MEGA) for macOS. Molecular Biology and Evolution 37, 1237-1239. Article

Stephens K, Measey J, Reynolds C, \& Le Roux JJ (2020) Occurrence and extent of hybridisation between the invasive Mallard Duck and native Yellow-billed Duck in South Africa. Biological Invasions 22, 693-707. Article

Stuart YE, Campbell-Staton SC, Hohenlohe PA, Reynolds GR, Revell LJ, \& Losos JB (2014) Rapid evolution of a native species following invasion by a congener. Science 346. Article

Todesco M, Pascual MA, Owens GL, Ostevik KL, Moyers BT, Hübner S, Heredia SM, Hahn MA, Caseys C, Bock DG, \& Rieseberg LH (2016) Hybridization and extinction. Evolutionary Applications 9, 892-908. Article

Tollis M, Ausubel G, Ghimire D, \& Boissinot S (2012) Multi-Locus Phylogeographic and Population Genetic Analysis of Anolis carolinensis: Historical Demography of a Genomic Model Species. PLOS ONE 7, e38474. Article

Wegener JE, Pita-Aquino JN, Atutubo J, Moreno A, \& Kolbe JJ (2019) Hybridization and rapid differentiation after secondary contact between the native green anole (Anolis carolinensis) and the introduced green anole (Anolis porcatus). Ecology and Evolution 9, 4138-4148. Article 